\title{
$(0-5$ \\ ROLE OF HYSTEROSALPINGOGRAPHY IN MANAGEMENT OF FEMALE INFERTILITY AND ITS LAPAROSCOPIC CORRELATION
}

\section{Dr. (prof.) Alka Agrawal \\ Dr. Mitisha Dhosariya \\ Dr Shweta Kumari}

\section{Dr. Prem}

Siddharth Tripathi*
Professor \& HOD Department Of Radiodiagnosis, MGM Medical College \& M.Y. Hospital, Indore

Third Year Resident Department Of Radiodiagnosis, MGM Medical College \& M.Y. Hospital, Indore

Second Year Resident Department Of Radiodiagnosis, MGM Medical College \& M.Y. Hospital, Indore

Associate Professor, Department Of Radiodiagnosis, MGM Medical College \& M.Y. Hospital, Indore *Corresponding Author

ABSTRACT BACKGROUND : Infertility nowadays has become a medical as well as social problem.Laboratory findings alone is inconclusive in diagnosing infertility.HSG is the radiographic technique for evaluation of uterine cavity \& fallopian tubes..Direct visualization of abdominal and pelvic organs in laparoscopy allows a definite diagnosis where clinical examination \& less invasive techniques such as ultrasound \& HSG fail to identify the abnormality.

AIMS \& OBJECTIVES : To determine the role of HSG in the evaluation of infertility \& to correlate its findings with laparoscopy.

METHODS : 75 infertile females aged between 20-40 years were included. HSG \& laparoscopy was performed in all patients \& findings were analysed.

RESULTS : Sensitivity of HSG was $80 \%$,specificity was $76 \%$ with positive predictive value $63 \%$, negative predictive value $88 \%$ in detecting tubal pathology. Sensitivity of HSG in detecting uterine pathology was $67 \%$, specificity $73 \%$, positive predictive value $39 \%$ and negative predictive value $89 \%$.

CONCLUSION : HSG has reasonably good sensitivity \& specificity in diagnosing tubal \& uerine pathology while laparoscopy has diagnostic as well as therapeutic approach.Hence they are complimentary to each other in infertility work up.

KEYWORDS : (HSG) Hysterosalpingography, Laparoscopy, Infertility.

\section{INTRODUCTION :}

Infertility is defined by "the failure to achieve pregnancy after 12 months or more of regular unprotected sexual intercourse." This morbidity includes social, economic, relationship and psychological aspects. The work up of the patient should provide the clinician with useful prognostic information regarding possible future treatment.In addition, a wide arena of tests are available for the diagnosis of infertility. It is more important to perform the relevant investigation in a logical order at a correct time rather than performing routine tests in a series.Infertility affects about $10-15 \%$ of reproductive age couples ${ }^{2}$. WHO estimates that 60 to 80 million couples worldwide currently suffer from infertility 3 .Incidence of female infertility is $45.67 \%$.Infertility varies across regions of the world and is estimated to affect 8 to 12 per cent of couples worldwide ${ }^{3,5} \mathrm{WHO}$ estimates the overall prevalence of primary infertility in India to be between 3.9 and 16.8 per cent. Tubal and peritoneal factors along with uterine factors account for almost $30-40 \%$ of cases of female infertility and hence evaluation of tubal patency and uterine pathology represents a key step and a basic investigation in the assessment of infertile couple. ${ }^{4}$ Hysterosalpingography (HSG) plays an important diagnostic role in finding the cause of infertility and in deciding the line of management. HSG is a simple, safe, and minimally invasive radiologic procedure to visualize uterine cavity and tubes after contrast administration. Though pelvic sonography and HSG are good enough to exclude gross intrauterine pathology, however, subtle changes which influences fertility like small polyps, adhesions, and subendometrial fibroid seedling, can be missed. These changes are better appreciated on laparoscopy.

\section{MATERIALS \& METHODS:}

This prospective study was carried out in Department of Radiodiagnosis ,MGM Medical College \& M.Y. Hospital from April 2018 to April 2019 after ethical \& scientific committee clearance in which 75 patients with infertility aged between $20-40$ years were included. These patients were referred from Department of Obstetrics \& Gynaecology for HSG which was performed between $8^{\text {th }}-11^{\text {th }}$ day of menstrual cycle. The patients with vaginal discharge, active PID , suspected pregnancy, recent uterine or tubal surgery (salpingectomy), active uterine or vaginal bleeding, palpable adnexal mass or tenderness on bimanual examination, male infertility factors and hormonal causes of infertility were excluded. Water soluble contrast medium was pushed through internal os and spot films were taken. Contour of uterus, fallopian tubes \& peritoneal spill was noted. In consecutive menstrual cycle, patient underwent laparoscopy under general anaesthesia after written consent. The findings were ananlysed . data was depicted in the form of tables and charts.

\section{RESULTS:}

Out of 75 patients, 40 patients (53\%) belonged to age group of $26-30$ years. Only 5 patients $(6 \%)$ above 36 years of age sought medical advice. About 38 patients(51\%) had 4-6 years of duration of infertility. HSG was normal in about 32 patients (43\%). 17 patients $(23 \%)$ had tubal abnormality, 11 patients $(15 \%)$ had uterine abnormality, while 15 patients $(20 \%)$ had tubal as well as uterine abnormality on HSG. Total tubal pathology was seen in 32 patients $(43 \%)$ and uterine pathology was seen in 26 patients (35\%). Out of 32 patients $(43 \%)$ with tubal pathology, blocked tubes were seen in 24 patients $(75 \%)$ and tubal patency were seen in 8 patients $(25 \%)$.

All the 75 patients underwent laparoscopy for further management of infertility which showed normal laparoscopic findings in 45 patients $(60 \%)$. Tubal pathology was seen in 15 patients $(20 \%)$, uterine pathology in 5 patients $(6 \%)$. About 10 patients $(13 \%)$ had tubal as well as uterine pathology. Total tubal abnormality was seen in 25 patients $(33 \%)$ and total uterine abnormality was noted in about 15 patients (20\%). Out of 25 patients with tubal abnormality, tubal block was seen in 13 cases (52\%) 12 patients (48\%) had patent tubes .Unicornuate uterus as seen on HSG turned out to have normal uterine cavity on hysterolaparoscopy.

The sensitivity of HSG in detecting tubal pathology in our study was $80 \%$, specificity of $76 \%$, positive predictive value of $63 \%$ and negative predictive value of $88 \%$. Sensitivity of HSG in detecting uterine pathology was $67 \%$, specificity of $73 \%$, positive predictive value of 39 $\%$ and negative predictive value of $89 \%$ was noted. 
Volume-9 | Issue-11 | November - 2019 | PRINT ISSN No. 2249 - 555X | DOI : 10.36106/ijar Table 1 Radiographic abnormalities of uterus and fallopian tubes on two modalities

\begin{tabular}{|c|c|c|c|c|}
\hline & & HSG & & DSCOPY \\
\hline & Number of cases & Percentage \% & Number of cases & Percentage $\%$ \\
\hline Normal finding & 32 & 43 & 45 & 60 \\
\hline Tubal abnormality only & 17 & 23 & 15 & 20 \\
\hline Uterine abnormality only & 11 & 15 & 5 & 6 \\
\hline Both uterine \& tubal abnormality & 15 & 20 & 10 & 13 \\
\hline $\begin{array}{l}\text { Total tubal pathology } \\
\text { Tubal block only } \\
\text { Block with hydrosalpinx } \\
\text { Patent with hydrosalpinx } \\
\text { Adhesion with hydrosalpinx }\end{array}$ & $\begin{array}{l}32 \\
17 \\
7 \\
3 \\
5\end{array}$ & $\begin{array}{l}43 \\
53 \\
22 \\
9 \\
15\end{array}$ & $\begin{array}{l}25 \\
10 \\
3 \\
5 \\
7\end{array}$ & $\begin{array}{l}33 \\
40 \\
12 \\
20 \\
28\end{array}$ \\
\hline $\begin{array}{l}\text { Total uterine pathology } \\
\text { Unicornuate } \\
\text { Bicornuate } \\
\text { Septate } \\
\text { Synechaie } \\
\text { Submucosal fibroid } \\
\text { Subserosal fibroid }\end{array}$ & $\begin{array}{l}26 \\
1 \\
5 \\
4 \\
16 \\
- \\
- \\
\end{array}$ & $\begin{array}{l}35 \\
3 \\
19 \\
15 \\
61 \\
- \\
- \\
\end{array}$ & $\begin{array}{l}15 \\
- \\
4 \\
5 \\
2 \\
3 \\
1 \\
\end{array}$ & $\begin{array}{l}20 \\
- \\
26 \\
33 \\
13 \\
20 \\
6\end{array}$ \\
\hline
\end{tabular}

Table 2 : Statistical analysis of HSG in tubal and uterine pathology

\begin{tabular}{|c|c|c|}
\hline & $\begin{array}{c}\text { TUBAL } \\
\text { PATHOLOGY }\end{array}$ & $\begin{array}{c}\text { UTERINE } \\
\text { PATHOLOGY }\end{array}$ \\
\hline Sensitivity & $80 \%$ & $67 \%$ \\
\hline Specificity & $76 \%$ & $73 \%$ \\
\hline Positive predictive value & $63 \%$ & $39 \%$ \\
\hline Negative predictive value & $88 \%$ & $89 \%$ \\
\hline
\end{tabular}

\section{DISCUSSION :}

Infertility has become a major reproductive health issue in developing countries. It directly affects couples socioeconomically and psychologically. In the era of newer advances in imaging modalities, early detection of any abnormality leading to infertility has become crucial. This can prompt in early management leading to less suffering of couples. Hysterosalpingography (HSG) plays an important diagnostic role in finding the cause of infertility and in deciding the line of management.on the other hand, Laparoscopy helps in visualizing hidden areas of pelvic cavity which are often missed on other imaging modalities . With this background, we have attempted to evaluate infertility cases by H.S.G. and later on by diagnostic laparoscopy.

In our study, majority of the cases belong to age group of 26-30 years $(53 \%)$ with duration of infertility being $4-6$ years in about $51 \%$

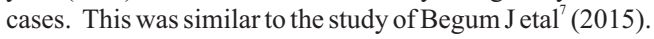

In our study, out of 75 patients, $43 \%$ patients had normal HSG findings. $23 \%$ cases contributed to tubal pathology, $15 \%$ to uterine pathology while $20 \%$ had tubal as well as uterine pathology. Total tubal pathology was seen in $43 \%$ while $35 \%$ contributed to uterine pathology on HSG. On laparoscopy , 45 patients $(60 \%)$ had normal findings. $20 \%$ patients had tubal pathology, $6 \%$ had uterine pathology while $13 \%$ had tubal as well as uterine pathology. Total tubal pathology was confirmed in $33 \%$ while uterine pathology was confirmed in $20 \%$.

In our study, out of 32 cases of tubal pathology, 24 cases (75\%) were found to have blocked tubes on HSG that included pure tubal block in 17 cases $(53 \%)$ and hydrosalpinx associated with block in 7 cases $(22 \%) .8$ cases $(25 \%)$ had patent tubes which included hydrosalpinx with and without adhesion in 5 cases $(15 \%)$ and 3 cases $(9 \%)$. On performing laparoscopy, 13 cases $(52 \%)$ out of 25 cases of tubal pathology, were found to have blocked tubes while 12 cases $(48 \%)$ had tubal patency. 5 cases $(20 \%)$ of hydrosalpinx and 7 cases $(28 \%)$ of adhesion contributed to tubal patency while 10 cases $(40 \%)$ had purely tubal block and 3 cases had hydrosalpinx along with tubal block. All the patent tubes were confirmed on laparoscopy. This was in accordance with Phillips et al who concluded that HSG leads to incorrect interpretation either false positive or false negative. The most problem is due to cornual block due to myometrial spasm.

In our study, most common uterine abnormality seen on HSG was synechaie in 16 cases $(61 \%)$ followed by mullerian anomaliesbicornuate in 5 cases (19\%), septate in 4 cases $(15 \%)$ and unicornuate in 1 case (3\%). This was similar to a study conducted by Wadhwa et al in which filling defects were common uterine abnormality.
In our study, the most common uterine abnormality on laparoscopy was septate uterus seen in 5 cases $(33 \%)$, followed by bicornuate uterus in 4 cases $(26 \%)$. This was in accordance with a study conducted by Maiti GD in which mullerian anomalies detected on HSG were confirmed on DHL.

In present study, the sensitivity of HSG for detecting tubal pathology was $80 \%$, specificity was $76 \%$, PPV $63 \%$, NPV $88 \%$. this was similar to study by Foroozanfard $\mathrm{F}^{6}$ where sensitivity and specificity of $\mathrm{HSG}$ in detecting tubal pathology was $77 \%$ and $52 \%$ resepectively.

Also, the sensitivity of HSG for detecting uterine pathology was $67 \%$, specificity was $73 \%$, PPV $39 \%$, NPV $89 \%$. This was similar to study by Chauhan et al. where sensitivity and specificity of HSG in detecting uterine pathology was $50 \%$ and $98 \%$ resepectively.

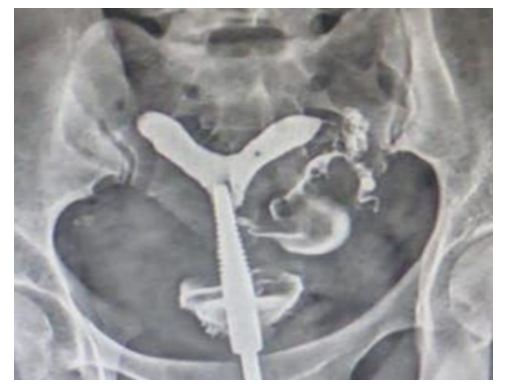

Figure 1: HSG showing bicornuate uterus with right proximal tubal block.

\section{CONCLUSION :}

HSG is a safe tool in screening the patients of infertility. Being less invasive, easily available, less expensive, it can be used as initial investigation for female infertility workup. The complication rate of HSG are also less as compared to laparoscopy. Laparoscopy, on the other hand, provides a wider field of view in detection of cause of infertility which is often missed on other imaging modalities. It can detect mullerian anomalies and can help in its management in the same sitting. From our study, we concluded that HSG can detect uterine abnormalities, but findings have to be confirmed by laparoscopy. Thus the two techniques are not alternative but complimentary to each other in female infertility work up.

\section{REFERENCES:}

1. Phillips, C. H., Benson, C. B., Ginsburg, E. S., \& Frates, M. C. (2015). Comparison of uterine and tubal pathology identified by transvaginal sonography, uterine and tubal pathology identified by transvaginal sonography,
hysterosalpingography, and hysteroscopy in female patients with infertility. Fertility

2. Chauhan MB, Lakra P, Nanda S, Malik R, Malhotra V. Hysterosalpingography vs hysteroscopy: role in assessment of uterine factor during infertility workup. J S Asian Fed Obstet Gynaecol 2013;5:116-9.

3. Wadhwa L, Rani P, Bhatia P. Comparative Prospective Study of Hysterosalpingography and Hysteroscopy in Infertile Women. J Hum Reprod Sci 2017;10:73-8.

4. Zvanca M, Vladareanu R, Andrei C. Infertility investigation through saline infusion sonohysterosalpingography. Maedica J Clin Med 2007;2(1):10-7.

5. Maiti GD, Lele P. Hysterosalpingography (HSG), hysteroscopy and laparoscopic evaluation of female genital tract of patient attending tertiary infertility centre and 601 .

6. Foroozanfard, F., \& Sadat, Z. (2013). Diagnostic value of hysterosalpingography and laparoscopy for tubal patency in infertile women. Nursing and midwifery studies, 2(2), $188-192$. 